\title{
ES POSIBLE DESARROLLAR LA COMPETENCIA ARTÍSTICA Y CULTURAL DESDE LA QUÍMICA
}

\author{
Ma Ángeles Sánchez Guadix \\ Profesora de Educación Secundaria. I.E.S Isabel la Católica. Guadahortuna (Granada) \\ E-mail: mulhacen1@hotmail.com
}

[Recibido en Junio de 2009, aceptado en Mayo de 2009]

\begin{abstract}
RESUMEN (Inglés)
Conseguir que el alumnado sea competente en todos los aspectos culturales de nuestra época es un objetivo muy loable. Lamentablemente, parece que las ciencias no puedan contribuir a dicho objetivo en los aspectos artísticos y culturales, ahondando de nuevo en la separación entre ciencia y cultura. En el presente artículo realizamos una reflexión, desde el punto de vista de la química, sobre dicha creencia para negarla.
\end{abstract}

Palabras clave: competencia artística y cultural; química y cultura; química y arte; química y poesía; química y cine.

\section{INTRODUCCIÓN: A VUELTAS CON EL DILEMA CIENCIA Y CULTURA}

"La ciencia es una forma artística no un método filosófico". Freeman Dyson.

Volver a insistir sobre el hecho de que la ciencia es cultura, sería seguir dando golpes a nuestras conciencias, porque en esto estamos todos de acuerdo, aunque, desgraciadamente, parece que no lo terminamos de creer. Basta con revisar algunas de las propuestas didácticas, especialmente de las editoriales de libros de texto, cuando hacen el esfuerzo de relacionar los contenidos de las materias científicas con las competencias que debe desarrollar cualquier persona al terminar sus estudios secundarios obligatorios. Si se trata de la competencia cultural y artística, en el mejor de los casos, directamente la obvian, y en el peor, encontramos textualmente: "todas las competencias citadas anteriormente, excepto la cultural y artística, tienen su presencia en el currículo de esta materia (Física y Química)..." Ante esta situación, tal vez de forma inconsciente, se vuelve a calar en nuestras mentes la idea de que sólo es culta aquella persona que tiene conocimientos humanísticos (históricos, literarios, artísticos, filosóficos o políticos), aunque sea casi analfabeta desde el punto de vista científico (Lloréns, 1991; Martín-Díaz et al, 2000).

Si leemos con avidez el libro de Schwanitz (2003), motivados por su sugerente título: "La cultura. Todo lo que hay que saber", tal vez, nos llevemos una desilusión al comprobar el poco peso de las ciencias en "todo lo que hay que saber". Quizás como 
respuesta a este vacío apareció poco después el libro "Vida, Naturaleza y Ciencia. Todo lo que hay que saber" de Ganten, Deichmann y Spahl (2004), aunque no tan popular como el primero. Ahora bien, es muy aconsejable la lectura de la revista digital mexicana Elementos: Ciencia y Cultura (www.elementos.buop.mx) para reponernos del sobresalto al pensar en la separación entre estos dos pilares de la Humanidad.

Para ser justos, es preciso hacer notar que el divorcio entre ambas culturas es un hecho mutuamente deseado, en palabras de Martínez Sáez (2000). Así en los planes de estudio de las carreras científicas se ignoran disciplinas como la epistemología, la lógica o la propia historia de la ciencia (Caamaño 2006); y, por su parte, quienes se dirigen a estudios de carácter humanístico, suelen ver, en las matemáticas o en las ciencias de la naturaleza, al mismísimo diablo. La situación se agrava en el caso de la Química. Fochi (2001) nos recuerda que existe un pensamiento social generalizado tendente a considerar que estar totalmente falto de conocimientos en este ámbito es una laguna sin importancia para quien se considera (o pretende ser) una persona culta. Como todos los prejuicios, también éste se basa en presuposiciones equivocadas o distorsionadas. Dentro de estos prejuicios, como manifiesta Pinto (2003), encontramos la identificación exclusiva de la Química con los problemas medioambientales, como ya expuso la sección de Educación de la Sociedad Americana de Química hace unos años: "la comprensión de la Química por parte de la ciudadanía es pobre, al percibir en gran medida que los productos químicos contaminan el medio ambiente y sin apreciar las implicaciones de esta Ciencia en la vida diaria".

Cachapuz (2007) lamenta que en el ámbito de la educación en ciencias, las contribuciones acerca de las relaciones arte y ciencia son escasas y muy recientes. En esta línea hemos de citar el curso "Química y Cultura Científica" dentro el programa de formación del profesorado de la UNED (Esteban y Pérez-Esteban, 2008)

Tanto la ciencia como el arte, insistimos, si acaso son cosas distintas, de acuerdo con Shortland (citado en Laugksch 2000), pretenden llegar a una interpretación de lo que nos rodea para transmitir sus conclusiones a otras personas $y$, en ambos casos, se requieren habilidades técnicas. Sin embargo, existe una diferencia esencial entre ambas intenciones: los científicos estudian las percepciones de los sentidos, ayudándose del instrumental especialmente diseñados para ello, de modo cuantitativo para revelar leyes y concretar conceptos que nos permitan el estudio de la naturaleza. Los artistas, en cambio, seleccionan las percepciones cualitativamente y las ordenan de forma que manifiesten su propia comprensión personal y cultural. Además los científicos están sujetos a continuas revisiones de su trabajo, de manera que las leyes científicas pueden quedar invalidadas en aras de nuevos descubrimientos. Una obra de arte, aunque cambien los gustos, tiene un valor estético o literario permanente como fruto de una época o estilo. Lightman (2005) nos muestra la dualidad, a veces dolorosa, pero enriquecedora de sus facetas como científico y literato.

La principal razón, según Cachapuz (2007), para desarrollar reflexiones sobre los caminos cruzados del arte y de la ciencia estriba en ayudar a promover un objetivo central (pero casi siempre retórico) de la educación en general, y de la educación en ciencia en particular, como es la educación para la interdisciplinaridad. Si a esta razón le añadimos la necesidad de fomentar en el alumnado la creatividad con el 
conocimiento adquirido, nos tenemos que preguntar: ¿realmente la química no contribuye al desarrollo de competencias culturales y artísticas?

\section{COMPETENCIA ARTÍSTICA Y CULTURAL CON-CIENCIA QUÍMICA}

Esta competencia supone el desarrollo de habilidades para expresarse movilizando los recursos creativos y para apreciar y disfrutar con las distintas manifestaciones del arte y de la cultura. Desde la química podemos y debemos fomentar esta creatividad, puesto que son numerosas las relaciones entre esta disciplina y el arte. Consideraremos algunos aspectos y sus posibles aplicaciones en el aula que, según las palabras de Beyer (2003), nos permitirán introducirnos en la fascinante química y agudizar nuestra conciencia.

\section{La química y el arte}

La relación entre los materiales, por tanto la química, y el arte comenzó el mismo día, allá por los albores de la Humanidad (Lerman, 2003). Baste aquí considerar la evolución del arte con los nuevos pigmentos o materiales, las aportaciones de la química en el descubrimiento de fraudes artísticos o en la conservación y restauración de obras de arte (Cuenca 2003, Ruiz et al 2004, Wamba y Jiménez, 2005) y, por qué no, las representaciones de laboratorios y de científicos o alquimistas en las obras de Berckheyde, Düver, etc, o en la abundante filatelia científica. Recientemente encontramos en las librerías una pequeña joya con un sugerente título: "iViva la Ciencia!" (2008), pues bien en ella, se unen el ameno texto sobre la historia de la ciencia y las ilustraciones del maestro Antonio Mingote.

El primer libro publicado en castellano que relaciona ambas disciplinas data de principios del siglo XIX: "Curso de química general aplicada a las artes" (1804-1805) de José María San Cristóbal y Joseph Garriga i Buach (García y Bertomeu, 2002).

El arte, concretamente la pintura, también se ha inspirado en distintos compuestos o conceptos químicos, baste consultar obras como:

"Petróleo" de Patrick Soper, "Macro:Micro" de Mari May, "Sublimación" de Nicole Sadin, "Agua y aire" de M.C. Escher, "Pressure" de Chirstina Thompso, "Density" de David Preissel, "Oxígeno" de Wolf, "Dissolving" de Cai Xiaohua, "Carbono" de N. Desprez, "Lysergic Acid Diethlamide" de Tomy Kremp, "Entropy" Irma M. HighoferSzalkay, "Alchemy" de Pollock, "Energía en suspensión" de Kandinsky, "Los atributos de las Ciencias" o "El Alquimista" ambos de Jean-Simeon Chardin..., probablemente después de acercarnos al estudio de estos conceptos, nuestra percepción de la obra artística sea distinta; es el momento de dejar salir la creatividad del alumnado para que éste exprese libremente sus nuevos sentimientos y conocimientos ante estas obras. Mención especial merece el caso de Salvador Dalí, si consideramos su faceta de intentar fusionar arte y ciencia y su interés por los descubrimientos científicos de su época, que inevitablemente se trasladan a su obra (López Ferrado, 2006). En la línea propuesta se pueden analizar cuadros como "Galadesoxyrribonucleicacid" o "Leda atómica". 
Las relaciones entre la química y el arte se pueden reforzar con experiencias de reproducción de técnicas pictóricas, similares a los propuestos con los talleres renacentistas (Carretero y Sánchez, 2007 o Gonzalo et al, 2008) o bien, con concursos inspirados en la emisión del sello conmemorativo del centenario de la muerte del químico ruso Mendeléiev (García y Román, 2008). Dicho sello, diseñado por Javier García, está basado en los trabajos de Mondrian, respeta la historia de la química y los estudios Mendeléiev.

Evidentemente este refuerzo debe ir acompañado con visitas, aunque sean virtuales, a exposiciones artísticas. Un buen ejemplo sería "El color de la química" nombre de la exposición de Toni Soriano, en el Centro de Escultura de Candas. Este artista asegura que el color de la química es el de la cerámica, y su estudio puede ser la guinda de los contenidos relativos a la oxidación-reducción.

También puede ser interesante relacionarnos con artesanos, puesto que será bastante probable encontrar un taller cerca de nuestros centros de enseñanza, aunque estén separados espiritualmente años luz de nosotros, para nuestra desgracia. Una excelente guía para nuestro trabajo nos la puede proporcionar la publicación (2005, libro y DVDs) de la Consejería de Turismo, Comercio y Deporte: Fondo Andaluz para la Recuperación del Conocimiento Artesano. La idea sería llevar los saberes populares al aula, para, en palabras de Chassot (2007), iluminarlos con saberes académicos y convertirlos en saberes escolares. Una posible vía para ello serían las entrevistas personales, para ejercer cual periodista científico bien documentado (Sánchez Guadix et al, 2008).

\section{La química y la poesía}

"La alquimia enseña a separar lo falso de lo justo, al igual que la poesía". Paracelso

"Cualquiera que descubra una gran verdad científica se hallará precedido por un poeta". Frederic Wood Jones.

"La ciencia, como la poesía, no describe hechos. Crea imágenes". Niels Bohr.

"Los científicos expanden el horizonte de lo posible, igual que el arte y la literatura" Sofía Rhei

La presencia de la química, o la ciencia en general, en la poesía es un hecho bastante frecuente, aunque poco usado por el profesorado de ciencias. Borges señalaba que arte y ciencia son comparables al explicar un fenómeno determinado por el método de representación: ambos usan la metáfora como herramienta explicativa y materia de trabajo. Así, grandes literatos han bebido de la ciencia para saciar su sed creativa, por ejemplo, Coleridge asistía a las clases de química de Davy buscando metáforas (pensemos también en "Metáforas Químicas" de T. S. Eliot), o han buscado préstamos químicos, como Goethe en "Las afinidades electivas". En resonancia con lo anterior, el poeta y novelista francés Michel Houellebecq publicó "Las partículas elementales" en 1999, novela que integra magistralmente un discurso científico en la narración (Alanis, 2000).

No nos puede extrañar que todos los químicos tengan, o deberían tener, un poeta a mano en sus laboratorios como si fuese un matraz aforado o un mechero bunsen. 
Jorge de Arco, poeta de nombre y hechuras alquímicos, es uno de los que más resultado daría en los estantes de cualquier "Hermes Trimegisto", y más concretamente su libro "La constancia del agua" (2007).

Otros han compaginado grandes pasiones científicas y literarias, como podemos comprobar tras la lectura de "Los elixires de la ciencia: miradas de soslayo en poesía y prosa" de Enzensberger (Premio Príncipe de Asturias de Comunicación 2002). Road Hoffman, Premio Nobel de Química en 1981, es un ejemplo extraordinario de científicos poetas, puesto que en numerosas ocasiones ha manifestado como la escritura de poesía le ayuda a ser mejor científico. Científicos conocidos por todos han cultivado otras artes, así por ejemplo Einstein era un virtuoso del violín, Heisemberg del piano y Ostwald conciliaba el piano y la pintura con sus investigaciones científicas.

Gómez (2003) realiza un cuidadoso análisis del uso de términos químicos en obras de Novalis, ya que el siglo XVIII fue testigo del nacimiento de la química como ciencia, y la fascinación por sus experimentos se transvasa a la literatura. Estamos ante la poesía descriptiva y didáctica de principios del siglo XIX, donde el objetivo es describir la naturaleza para mostrar su más profundo sentido de la armonía. En un artículo de Dhombres (2002) disfrutamos de interesantes poemas de este género. En la literatura castellana podemos comprobar los enlaces entre química, farmacia y poesía con el artículo de Francés y del Valle (2001). Mención especial merece la obra de María Cegarra Salcedo llena de fórmulas, que representan la exactitud y la verdad, de útiles de laboratorio, de sonidos y procesos experimentales, de elementos y minerales, así como de las minas de su tierra (Díez de Revenga, 2003).

Recientemente, Sofía Rhei presentó su libro "Química" (2008), un poemario que intenta fusionar el mundo de la ciencia con el de la poesía, aunque algunos piensen que se trata de mundos antagónicos. Además, este libro tiene la peculiaridad de que las palabras que generaron los versos están formadas a partir de sílabas de la tabla periódica. Una experiencia didáctica, cercana a esta idea y previa a la publicación del libro de Rhei, la desarrolló Peña (2007) proponiendo el aprendizaje de los símbolos de los elementos químicos mediante un juego sencillo: la construcción de palabras y frases utilizando dichos símbolos.

Otra experiencia didáctica que intenta unir ambos mundos es la presentada por Mendoza (2004). En ella, y con el objetivo, entre otros, de hacer la enseñanza de la química más emotiva y creativa, se promueve un concurso de Poesía Química utilizando un lenguaje químico basado en conceptos reales de la materia. En el trabajo citado podemos encontrar los poemas, cartas y relatos ganadores que nos pueden servir de inspiración para promover concursos similares o para usarlos en clase. El análisis crítico de estos poemas u otros[1], con el alumnado podría ser tan útil como algunos fragmentos de los libros de texto, por no decir que más.

\section{La estética de la química}

Los avances científicos y tecnológicos por los que atraviesa la humanidad, son el legado de años de observaciones, comparaciones e imitaciones que se han hecho de la Naturaleza. Los elementos y los compuestos, en sus diferentes estados, involucran 
una belleza inherente, como en el arte, donde también la simetría es de vital importancia.

La síntesis química o la cristalización mineral, se puede comparar con la creación de una pintura o una escultura, e involucra, en consecuencia, una creatividad artística, por ejemplo, si se descubre un camino elegante de síntesis para un compuesto o para justificar su estructura en función de sus propiedades, (pensar en el fullereno). Con estas ideas podríamos fomentar concursos de fotografía bajo el lema: La Naturaleza imita a la química (o al contrario).

En nuestras aulas y laboratorios también podemos encontrar momentos que inspiren al más avezado fotógrafo por la belleza de la química. Por ejemplo, el estudio de las reacciones ácido base está presente en la mayoría de las programaciones, y la neutralización puede ser estéticamente atractiva. En http://www.geology.yale.edu/ mgw22/Acid base/ podemos consultar una secuencia de imágenes que nos muestra la reacción entre una disolución ácida (roja) y una básica (azul) inyectadas en una cubeta cada 20 segundos y fotografiada cada minuto. Otra práctica que permite recrear un "arco iris" de color es la adición de bromo al zumo de tomate. Éste contiene licopeno, compuesto insaturado de color rojo, que cuando adiciona bromo a sus dobles enlaces, cambia de color. Si al zumo de tomate le adicionamos una disolución saturada de bromo con un gotero y sobre una varilla agitadora conseguiremos, por un gradiente de concentración, distintos colores y por tanto un efecto de arco iris.

\section{LA QUÍMICA Y CINE}

Son numerosas las propuestas didácticas que usan como recurso motivador el cine y los dibujos animados (Vílchez y Perales, 2005). Numerosos ejemplos de estas propuestas las podemos encontrar en Guerra 2004, así mismo, podemos ampliar el banco de recursos consultando la página de la asociación española de cine e imagen científicos, www.asecic.org, o bien en www.auladecine.com). La mayoría de estos proyectos tienen el loable objetivo de criticar la falta de rigor y respeto a las leyes científicas, o bien, reflexionar sobre la imagen distorsionada de la ciencia, y como no, propiciar debates ético-científicos (Guerra Retamosa 2004). García Borrás (2009) elabora fichas de las películas bienvenidas a la enseñanza de las ciencias, cual Mister Marshall, en las que considera los aspectos científicos a investigar junto a los objetivos didácticos alcanzables con su estudio.

Miguel Barral ha publicado recientemente el libro "Que la ciencia te acompañe: encuentros y desencuentros entre los científicos y el cine" (2008). Para cada una de las películas analizadas, después de presentar la correspondiente ficha técnica y sinopsis, se transcriben fragmentos de diálogos y se invita al lector a descubrir el gazapo científico, para ofrecer posteriormente una amena explicación. Para el caso de la química, se analizan películas como El Gran Halcón, Misión Imposible II, Timecop policía en el tiempo, El sonido del trueno, El Código da Vinci, Últimos días del Edén... Didácticamente sería aconsejable, según las sugerencias del propio autor, que fuese el propio alumnado quien intentase descubrir el gazapo y buscar la justificación. En cualquier caso nos sirven para estudiar, afianzar o profundizar en contenidos tales 
como la tabla periódica, propiedades características de los elementos, combinaciones atómicas y sus diferencias con los átomos que las forman, etc, y para descubrir errores científicos de peso como la imposibilidad de realizar la prueba del carbono a un lingote de oro como pretendía Timecop.

Ahora bien, desde la perspectiva del trabajo que estamos abordando nos parece más interesante proponerle al alumnado la preparación de guiones de cortos cinematográficos con temática científica $y$, si fuese posible, su posterior rodaje. 0 sin ser tan ambiciosos, podríamos rescribir el diálogo de las escenas estudiadas. Será en esta labor donde aparecerán la creatividad, la imaginación y la capacidad especulativa en su máximo esplendor, cimentadas en el aprendizaje y aprovechamiento de conceptos científicos (Palacios, 2007).

Como fuente de inspiración para trabajos con el alumnado sería muy recomendable la lectura de "El Químico de los Lumière" de Pedro García Martín (Algaida, 2008), ganador del XII Premio de Novela Ciudad de Salamanca. Se trata de una encantadora novela, protagonizada por un personaje ficticio, el químico, en el mundo real del frenesí inventor y el impresionismo de finales del S XIX, donde se aúna química, pintura y fotografía, con el objetivo de encontrar la foto en color, y aderezada con una trágica historia de amor. En definitiva una perfecta unión entre todos los elementos culturales: historia, ciencia, arte, literatura..., iqué más podemos pedir! Pues también viene acompañada de un DVD titulado "Cazadores de imágenes en la Belle Ėpoque", sobre la historia de la fotografía y el cine.

\section{CONCLUSIÓN}

Con los ejemplos propuestos, que no son más que la punta del iceberg, queremos demostrar que el alumnado puede reforzar el conocimiento de la química utilizando su creatividad mediante el uso del cuento, la parodia, la poesía, el acróstico, el teatro (vibrando, saltando y escapando cual moléculas), la pintura, la artesanía... Probablemente, la exclusiva memorización de conceptos esté avocada al olvido y, de cualquier manera, no implica dominar competencias propias del estudio de la ciencia como: habilidad para pensar, reflexionar, sintetizar, expresarse verbalmente o por escrito, interactuar, apropiarse creativamente del conocimiento e integrarlo como parte de la vida.

"Estoy muy contento de vivir entre ustedes, personas jóvenes y felices. Si un viejo estudiante pudiera decirles unas palabras serían éstas: Nunca tomen el estudio como un deber, sino como la envidiable oportunidad de aprender a conocer la influencia liberadora que la belleza ejerce en el espíritu para alegría personal de ustedes y beneficio de la comunidad a la que pertenecerá su trabajo futuro". Albert Einstein a estudiantes de nuevo ingreso a la Universidad de Princeton. 


\section{REFERENCIAS BIBLIOGRÁFICAS}

Arco, J. De. (2007). La constancia del agua. Editorial La Garúa.

Alanis. S. (2000). La ciencia de la narración. A propósito de Las partículas elementales de Michel Houellebecq. Elementos, 39, pp 51-56. Disponible en: www.elementos.buop.mx

Barral, M. (2008). Que la ciencia te acompañe: encuentros y desencuentros entre los científicos y el cine. Le pourquoipas editores.

Beyer, L. (2003). La Química y el Arte. Rev. Soc. Quím. Perú 69. No 3 (163-181). Disponible en www.sisbib.unmsm.edu.pe/bibvirtualdata/publicaciones/rsqp/n3-2003/a07.pdf.

Cachapuz, A. (2007) Arte y ciencia: ¿Qué papel juegan en la educación en ciencias. Revista Eureka sobre Enseñanza y Divulgación de las Ciencias, 4(2), pp 287-294. Disponible en: www.apac-eureka.org/revista/Volumen4/Numero $42 /$ Cachapuz 2007.pdf

Caamaño, A. (2006). Proyectos de ciencias entre la necesidad y el olvido. Alambique, 48, pp 10-24.

Carretero, M.B. y Sánchez Guadix, M.A. (2007) Recuperar el afán de conocimientos de Leonardo da Vinci en la era de las nuevas tecnologías: Arte, ciencia y vida cotidiana. Revista Eureka sobre Enseñanza y Divulgación de las Ciencias, 4(3), 526-538. Disponible en: www.apaceureka.org/revista/Volumen4/Numero 4 3/Carretero S\%E1nchezGuadix 2007.pdf

Chassot, A. I. (2007). Haciendo educación en ciencias en los estudios de Pedagogía con la inclusión de saberes populares en el currículum. Alambique, 51, pp 20-27.

Cuenca (2003) Análisis de concepciones sobre la enseñanza del patrimonio en la Educación Obligatoria. Enseñanza de las Ciencias Sociales, 2, pp 35-45.

Díez de Revenga Torres (2003). Lengua poética y lengua técnica: creación y ciencia. XXVI Curso de Lingüística Textual. Universidad de Murcia. Disponible en: www.seneca.uab.es/neolcyt/Estudios/Mineria/rev2003.pdf

Dhombres, N. (2002). Ciencia, poesía, romanticismo. Disponible en: www.gobiernodecanarias.org/educacion/3/Usrm/fundoro/SR2002_Capitulos/Par te I/I 3 SR2002-web.pdf

Enzensberger (2002). Los elixires de la ciencia: miradas de soslayo en poesía y prosa. Anagrama.

Esteban Santos, S. y Pérez-Esteban, J. (2008). Propuesta de un curso sobre química y cultura científica para la formación continua del profesorado. En Jiménez Liso, R. (Ed.) Ciencias para el mundo contemporáneo y formación del profesorado en Didáctica de las Ciencias Experimentales. Actas de los XXIII Encuentros de Didáctica de las Ciencias Experimentales. Editorial Universidad de Almería. pp 662-669. Disponible en www.23edce.com 
Fochi, G. (2001). El secreto de la Química. Un viaje por las múltiples e insospechadas aplicaciones de la química en la vida cotidiana. Editorial Man non troppo. Barcelona.

Francés Causpé, M.C. y del Valle Nieto, A. (2001). La farmacia en el Arte. Poesía y farmacia. Acta-Congressus Historiae Pharmaciae. Disponible en: www.cfscls.cz/Files/nastenka/page 3024/Version1/La\%20Farmacia\%20en\%20el \%20Arte.pdf

Ganten, Deichmann y Spahl (2004). Vida, Naturaleza y Ciencia. Todo lo que hay que saber. Ediciones Taurus.

García Belmar, A. y Bertomeu Sánchez, J.R. (2002) El curso de química general aplicada a las artes (1804-1805) de José María San Cristóbal y Joseph Garriga i Buach. En J.L. Barona et al. La Ilustración y las ciencias. Valencia, PUV, 179-237. Disponible en: www.uv.es/=bertomeu/pub/garriga.pdf

García Borrás, F. J. (2009) Bienvenido Mister Cine a la enseñanza de las ciencias. Rev. Revista Eureka sobre Enseñanza y Divulgación de las Ciencias, 6(1), pp. 79-91. Disponible en: www.apac-eureka.org/revista/Volumen6/Numero 6 1/Garc \%Eda Borr\%E1s 2009.pdf

García Martínez, J. Román Polo, P. (2008). 2007, El año de Mendeléiev: una iniciativa para la divulgación de la Química. Anales de la Real Sociedad Española de Química, 104(1), pp 50-55.

Gómez Perales, M.J. (2003) La voluptuosidad en los alambiques: el uso de términos químicos en la obra Die Lehrlinge zu Sais de Novalis. Ibérica 6, 135-143. Disponible en: www.aelf.org/documents/texto6-Gperales.pdf

Gonzalo, I et al (2008). De la alquimia a la química. Simulación de un taller alquimista. Recrea la paleta de un pintor del renacimiento. Experiencia presentada en la feria de la ciencia de Madrid. Disponible en www.madrimasd.org/cienciaysociedad/feria/publicaciones/Feria5/31/REAlquimia.pdf.

Guerra Retamosa C. (2004). Laboratorios y batas blancas en el cine. Revista Eureka sobre Enseñanza y Divulgación de las Ciencias. 1(1), 52-63. Disponible en: www.apac-eureka.org/revista/Volumen1/Numero_1_1/Laboratorios_y batas blancas.pdf

Laugksch,R.C. (2000). Scientific literacy: a conceptual overview. Science Education, 84 (1), pp71-94.

Lerman (2003) Using the art to make chemistry accesible to everybody. Journal of Chemical Education, 80(11), pp:1234-1243

Lloréns, J.A. (1991). Comenzando a aprender Química. Ed. Aprendizaje Visor. Madrid.

Martín Díaz, MJ. et (2000). La Física y la Química en Secundaria. Narcea S.A. de Ediciones. Madrid.

Martínez Sáez; L. A.(2000). Cultura científico-técnica, ¿una contradictio in términis? Hacia una integración de la tecnociencia en la cultura. Libro II de actas del I 
Congreso sobre Comunicación Social de la Ciencia: Comunicar la ciencia en el siglo XXI. pp 116-120. Granada.

Mendoza Cruz, M. (2004). Poesía Química. Instituto Politécnico Nacional. Dirección de Publicaciones. México DF. Disponible en www.publicaciones.ipn.mx/PDF/1326.pdf

López Ferrado, M. (2006). La obsesión de Salvador Dalí por la ciencia. História, Ciencias, Saúde-Manguinhos, 13, 125-131. Disponible en: www.scielo.br/pdf/hcsm/v13so/07.pdf.

Palacios, S.L. (2007). El cine y la literatura de ciencia ficción como herramientas didácticas en la enseñanza de la física: una experiencia en el aula. Revista Eureka sobre Enseñanza y Divulgación de las Ciencias, 4(1), pp. 106-122. Disponible en:

www.apaceureka.org/revista/Volumen4/Numero 4 1/Palacios 2006.pdf

Peña Martínez, M. (2007). Palabras y frases creadas con los símbolos de los elementos. Revista Eureka sobre Enseñanza y Divulgación de las Ciencias, 4(3), pp. 557-559. Disponible en: www.apaceureka.org/revista/Volumen4/Numero 4 3/Pe\%F1a 2007 CR.pdf.

Pinto, G. (2003). Experiencias de la vida diaria en la enseñanza de la Química. En Pinto, G. Didáctica de la Química y Vida cotidiana. Sección de publicaciones de la ETS de Ingenieros Industriales. UPM pp 49-57 Madrid.

Rhei, S. (2008). Química. El Gaviero.

Ruiz, R. et al (2004). La alfabetización científica y el patrimonio: análisis de páginas web. En P. Díaz. La didáctica de las Ciencias Experimentales ante las reformas educativas y la convergencia europea. Universidad del País Vasco, pp: 435-439.

Sánchez Guadix, M. A. et al (2008). Entrevista a profesionales de limpieza, cocina y peluquería: un recurso para la búsqueda de información. En Jiménez Liso, R. (Ed.) Ciencias para el mundo contemporáneo y formación del profesorado en Didáctica de las Ciencias Experimentales. Actas de los XXIII Encuentros de Didáctica de las Ciencias Experimentales. Universidad de Almería. pp 160-168. Disponible en www.23edce.com

Sánchez Ron, J. M. y Mingote, A. (2008). iViva la Ciencia!

Schwanitz (2003). La cultura, Todo lo que hay que saber. Ediciones Taurus.

Vílchez J. M. y Perales F. J. (2005). Enseñando Física con Dibujos Animados. Enseñanza de las Ciencias. Número Extra VII Congreso.

Wamba, A. M. y Jiménez, R. (2005). La enseñanza y difusión del patrimonio y la alfabetización científica: relaciones ciencia, tecnología, sociedad y patrimonio. Enseñanza de las Ciencias, Número Extra VII Congreso.

[1] Como los de Rómulo de Carvalho/Antonio Gedeao (profesor/poeta), citados por Cachapuz (2007) o los de la poesía descriptiva de finales del S.XVIII y principios del XIX, representada por Charles Chenedollé o Chénier Hermès, entre otros. 


\section{IT'S POSSIBLE TO DEVELOP THE ARTISTIC AND CULTURAL COMPETENCE FROM CHEMISTRY}

\section{SUMMARY}

Teaching students to be proficient in every cultural aspect of our time is a most laudable aim. Unfortunately, it seems that Science cannot contribute to such an aim regarding cultural and artistic aspects, digging deeper into the widening gap between Science and culture once again. In the present article, we reflect on this belief chemically in order to deny it.

Key words: artistic and cultural competence; chemistry and culture; chemistry and art; chemistry and poetry; chemistry and cinema. 